\title{
Effects of different sub-lethal concentrations of plasticizer-Diethyl phthalate on Fresh water murrel, Channa striatus (Bloch)
}

\author{
K. Roy George*, G. N. Gokul and N. A. Malini \\ Post-Graduate and Research Department of Zoology, St. Thomas College Kozhencherry - 689641 (Kerala), INDIA \\ *Corresponding author. E-mail: dr.roygeorgek@gmail.com
}

Received: June 9, 2016; Revised received: December 8, 2016; Accepted: February 15, 2017

\begin{abstract}
In the present study, effects of exposure to different sub lethal concentrations of diethyl phthalate on hematological, biochemical and histological parameters of fresh water murrel, Channa striatus were evaluated. $\mathrm{LC}_{50}$ of DEP was determined and was found to be $70 \mathrm{ppm}$ for the present study. The experimental fishes were divided into control and DEP exposed groups. DEP exposed fish species were subjected to $0.4 \mathrm{ppm}, 4 \mathrm{ppm}$ and $40 \mathrm{ppm}$ concentrations of DEP and observed after an interval of 7, 14 and 21days. Exposure to sub lethal levels of DEP revealed significant decrease in haematological parameters due to anemic condition induced by impaired haem synthesis. Exposure to DEP caused reduction in level of protein in muscle $\left({ }^{*} 182.5,{ }^{*} 180.7,{ }^{*} 176.7,{ }^{*} 176.1,{ }^{*} 173.4,{ }^{*} 167.5\right.$ and *165.7) and liver (*104.7, ${ }^{*} 98.6,{ }^{*} 92.7,{ }^{*} 87.7,{ }^{*} 87.4,{ }^{*} 86.4,{ }^{*} 80.8,{ }^{*} 75.6$ and $\left.^{*} 68.6\right)$ due to impairment of protein synthesis. Levels of cholesterol in muscle and liver of DEP exposed fish were found to be decreased after treatment indicating either an inhibition of cholesterol biosynthesis in liver or reduced absorption of dietary cholesterol. Histopathological examination of liver of DEP exposed fish species showed necrosis in hepatocytes and cytoplasmic vacuolization. Histoarchitecture of kidney of DEP exposed fish species revealed shrinkage of glomeruli, glomerular distortion, vacuolization of tubular cells, necrosis and atrophy of renal tubules. As an endocrine disruptor, DEP interferes with the haematopoietic system metabolic machinery and histoarchitecture of organs of Channa striatus.
\end{abstract}

Keywords: Channa striatus, Diethyl phthalate, Necrosis, Plasticizer

\section{INTRODUCTION}

Diethyl phthalate (DEP) is one of the most extensively used industrial chemicals in existence. With the exception of being used mainly as plasticizers, to provide elasticity, feasibility and sturdiness to polymers, DEP is also employed in products such as insecticides, mosquito repellants, camphor substitute, plasticizer for cellulose, bathing soaps, cosmetics, pharmaceutical coatings, after shave-lotion, detergent, ester plastic film and sheets etc. (Huang et al., 2008). To impart flexibility, phthalate esters are not chemically bonded to resin and therefore, are easily leached out. Diethyl phthalate in aquatic environment derives from various compounds of anthropogenic sources such as pesticides, detergents and plasticizers (Fatoki et al., 2010).

Great concern about the effect of these chemicals in environment has evolved due to their endocrinedisrupting properties. Researchers provide evidence that environmentally relevant concentrations of di(2-ethylhexyl)-phthalate (DEHP) interfere with zebra fish reproductive performance, representing a concrete risk for the aquatic population living in polluted areas. Exposure of female zebra fish to DEHP led to a significant increase of circulating levels of vitellogenin, supports the hypothesis that DEHP has estrogenic effects in zebra fish (Uren-Webster et al., 2010). Umamahe- swari and Senthilnathan (2014) reported that toxic stress caused by dibutyl phthalate (DBP) in Oreochromis mossambicus showed significant increase in acid phosphatase (ACP) and succinate dehydrogenase (SDH) activity of gill, liver and muscle. DEP has altered acid phosphatase (ACP), alkaline phosphatase (ALP), succinate dehydrogenase (SDH) and lactate dehydrogenase (LDH) activity in various tissues (gill, liver and muscle) of Tilapia (Umamaheswari and Senthilnathan, 2013). DEP was toxic to fish and causes histo pathological changes in kidney and liver of $C$. gariepinus (Ikele et al., 2011). In the present study, effects of exposure to different sub lethal concentrations of DEP on hematological, biochemical and histological parameters of the fresh water murrel, Channa striatus were evaluated.

\section{MATERIALS AND METHODS}

Channa striatus (O. Perciformes, F.Channidae) selected for the present study was collected from a fish farm near Pannivelichira (a Government of Kerala undertaking), Kozhencherry Taluk, Pathanamthitta District, Kerala, India. Healthy fishes of comparable body weight $(88 \pm 6 \mathrm{~g})$ and length $(25 \pm 4 \mathrm{~cm})$ were selected for the study. The fishes were treated with $0.05 \%$ $\mathrm{KMnO}_{4}$ solution for 2 min to clear any external infection. They were then transferred to $100 \mathrm{~L}$ capacity glass 
LC 50 of DEP using Probit analy sis (Finney method)

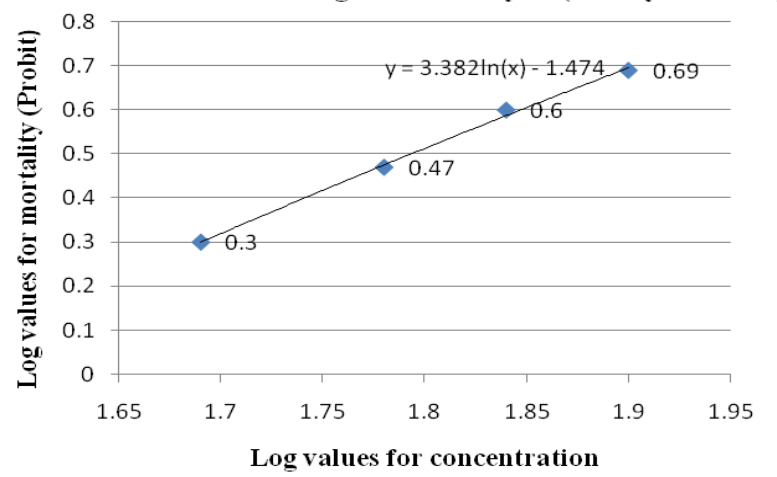

Fig. 1. Determination of $L C_{50}$ value of $D E P$ in Channa striatus (Log value for $50 \%$ mortality is 0.6 and log concentration for 0.6 is 1.84. Antilog of 1.84 is 69.2 and this was found to be $L C_{50}$ of $D E P$ ).

tanks filled with dechlorinated water one week prior to the experiment for acclimatization to laboratory conditions. A minimum of 4 fishes were introduced in each tank. The tanks were provided with continuous aeration and were maintained under normal day - night light duration. Feeding was carried out with oil cakes during the acclimation and stopped $24 \mathrm{~h}$ prior to experimentation. The water was changed after every 24 hours. Every effort was made to provide healthy condition for the fish and no mortality occurred during this period.

Diethyl phathalate $(99.99 \%)$ was procured from the Central Drug House, Mumbai. Stock solution was prepared by dissolving $1 \mathrm{ml}$ of DEP in $9 \mathrm{ml}$ distilled water (10 times dilution). Test concentrations were prepared by diluting appropriate aliquots of the stock solution. $\mathrm{LC}_{50}$ of DEP was statistically determined using probit analysis based on Finney (1950) method (Fig.1). For this, a preliminary range finding assay was conducted in which eight fishes each were randomly selected from the stock and exposed to increasing test concentrations of DEP (10ppm, 20ppm, 30ppm, 40ppm, 50ppm, 60ppm, 70ppm and 80ppm) for 96 hours. Water was changed every day with fresh DEP mixed water to sustain stable level of DEP throughout exposure period. The $\mathrm{LC}_{50}$ value for $\mathrm{DEP}$ was found to be $70 \mathrm{ppm}$. For the experiment, three sub-lethal concentrations (i.e. $0.4 \mathrm{ppm}, 4 \mathrm{ppm}$ and $40 \mathrm{ppm}$ ) were selected along with a negative control. Observations were made on 7 th, $14^{\text {th }}$ and $21^{\text {st }}$ day of the experiment.

At the end of the $7^{\text {th }}, 14^{\text {th }}$ and $21^{\text {st }}$ day, the fishes belonging to the respective groups were sacrificed by decapitation and blood samples were collected in Eppendorf tubes (containing EDTA anticoagulant) for determination of haematological parameters. Erythrocyte constants were determined as described by Cyril and Eric (1979). RBC count and WBC count were done using the Neubauer haemocytometer. The hemoglobin concentration was estimated by Sahli's method. The muscle and liver tissue were isolated, blotted free of blood and used for the estimation of protein and cholesterol. The estimation of protein was done by Folin - Ciocalteu method of Lowry et al (1951). The estimation of cholesterol was done by Zak's method (1977). Pieces of kidney and liver were dissected out from all the groups and processed for histological examination adopting the standard methods such as fixation, dehydration, embedding, sectioning and staining. Bouin's fixative is used for fixation and the tissue was dehydrated by treating them in various grades of alcohol ranging from $30 \%$ to $100 \%$ followed by clearing them with xylene. Then the samples were embed-

Table 1. Haematological parameters (Mean \pm SE) in control and DEP exposed fish.

\begin{tabular}{llcccc}
\hline Parameter & Days & Control & 0.4ppm & 4ppm & 40ppm \\
\hline RBC count (millions $/ \mathrm{mm}^{3}$ ) & DAY 7 & $3.72 \pm 0.3$ & $3.54 \pm 0.2$ & $3.10 \pm 0.4$ & $* 2.86 \pm 0.9$ \\
& DAY 14 & $3.72 \pm 0.3$ & $3.50 \pm 0.5$ & $3.01 \pm 0.8$ & $* 2.67 \pm 0.5$ \\
& DAY 21 & $3.72 \pm 0.3$ & $3.10 \pm 0.8$ & $* 2.97 \pm 0.7$ & $* 2.51 \pm 0.9$ \\
WBC Count(cells/mm ${ }^{3}$ ) & DAY 7 & $13032.33 \pm 1.5$ & $12939 \pm 1.2$ & $* 12725.5 \pm 1.8$ & $* 11612.5 \pm 1.2$ \\
& DAY 14 & $13032.33 \pm 1.5$ & $12912.8 \pm 1.4$ & $* 12719 \pm 1.9$ & $* 11491.8 \pm 1.5$ \\
Haemoglobin (g \%) & DAY 21 & $13032.33 \pm 1.5$ & $12854.3 \pm 1.5$ & $* 12353.5 \pm 1.4$ & $* 11215.8 \pm 1.3$ \\
& DAY 7 & $11.7 \pm 0.4$ & $11.5 \pm 0.8$ & $11.3 \pm 0.6$ & $11.1 \pm 0.8$ \\
Lymphocyte (\%) & DAY 14 & $11.7 \pm 0.4$ & $11.4 \pm 0.5$ & $11.1 \pm 0.8$ & $* 10.7 \pm 0.4$ \\
& DAY 21 & $11.7 \pm 0.4$ & $11 \pm 0.8$ & $* 10.8 \pm 0.4$ & $* 10.4 \pm 5$ \\
Packed Cell Volume (\%) & DAY 7 & $27.6 \pm 0.5$ & $25 \pm 0.4$ & $* 20.8 \pm 0.3$ & $* 18.2 \pm 0.3$ \\
& DAY 14 & $27.6 \pm 0.5$ & $23.8 \pm 0.2$ & $* 20 \pm 0.3$ & $* 16.6 \pm 0.5$ \\
Mean Cell Volume(fL) & DAY 21 & $27.6 \pm 0.5$ & $* 22.1 \pm 0.2$ & $* 16.4 \pm 0.2$ & $* 16 \pm 0.3$ \\
& DAY 7 & $10.92 \pm 0.1$ & $10.8 \pm 0.1$ & $10.74 \pm 0.1$ & $10.32 \pm 0.1$ \\
& DAY 14 & $10.92 \pm 0.1$ & $10.62 \pm .03$ & $10.1 \pm 0.03$ & $* 8.8 \pm 0.04$ \\
Mean Cell Haemoglobin (pg) & DAY 21 & $10.92 \pm 0.1$ & $10.38 \pm 0.01$ & $* 9.21 \pm 0.03$ & $* 8.16 \pm 0.02$ \\
& DAY 7 & $120 \pm 0.9$ & $119 \pm 0.4$ & $116 \pm 0.2$ & $* 101 \pm 0.8$ \\
& DAY 14 & $120 \pm 0.9$ & $116 \pm 0.5$ & $* 114 \pm 0.8$ & $* 98 \pm 0.5$ \\
& DAY 21 & $120 \pm 0.9$ & $* 115 \pm 0.8$ & $* 102 \pm 0.9$ & $* 95 \pm 0.3$ \\
& DAY 7 & $31.53 \pm 0.8$ & $29.8 \pm 0.5$ & $* 27.5 \pm 0.4$ & $* 25.8 \pm 0.5$ \\
& DAY 14 & $31.53 \pm 0.8$ & $28.5 \pm 0.3$ & $* 26.8 \pm 0.6$ & $* 24.8 \pm 0.8$ \\
& DAY 21 & $31.53 \pm 0.8$ & $28.2 \pm 0.4$ & $* 26.2 \pm 0.5$ & $* 24.2 \pm 0.4$ \\
\hline
\end{tabular}

*significant $(\mathrm{p}<0.05)$ 


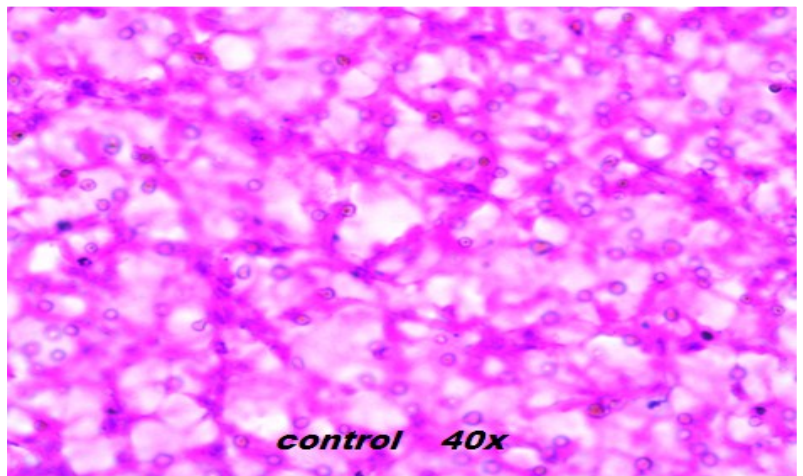

Fig. 2 A. Photomicrograph of liver section from control fish (X 40 magnification).

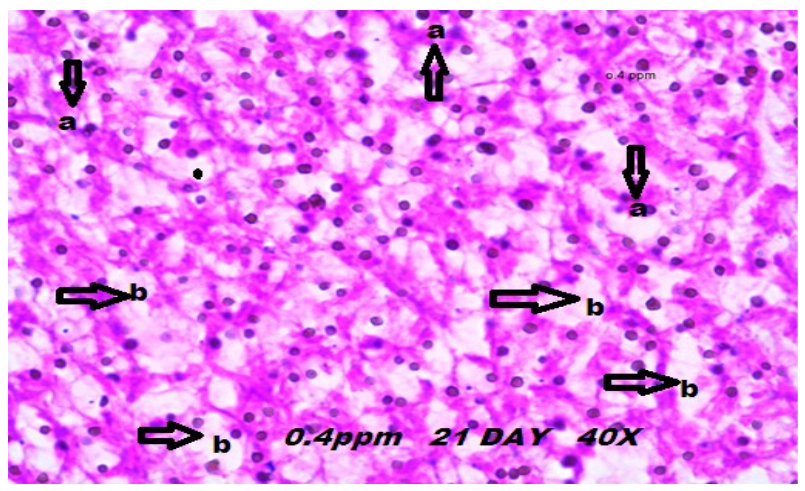

Fig. 2 B. Photomicrograph of liver section of DEP $(0.4 \mathrm{ppm})$ exposed (day 21) fish. (a) necrosis and (b) cytoplasmic vacuolation (X 40 magnification).

ded in the paraffin wax and the sections were double stained with haemotoxylene and eosine. The sections were cut at $5 \mathrm{~mm}$ thickness using microtome. The stained slides were examined with the help of compound microscope. Photomicrographs were taken using Lumenera- Infinity 1 (Model N9032789) camera fitted to the Olympus S761 (Model SZ2-ILST) research microscope.

\section{RESULTS AND DISCUSSION}

Diethyl phthalate is used in pharmaceutical coating, as a fixative in cosmetics, in the manufacture of celluloid, as solvent for cellulose acetate in the manufacture of

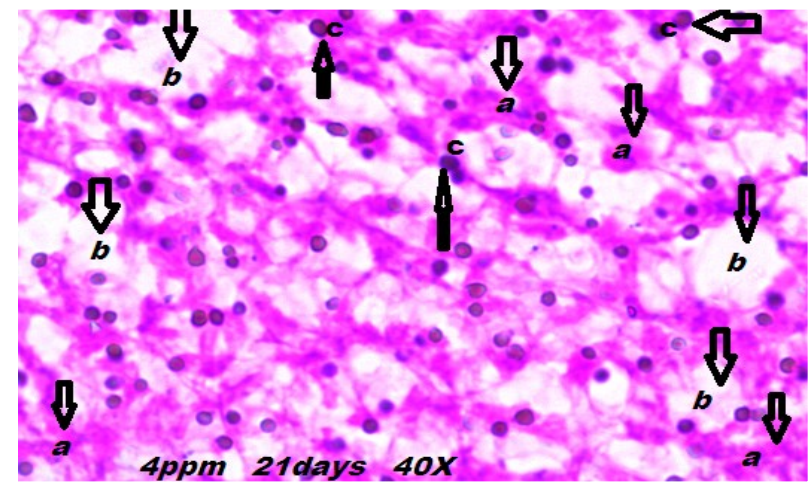

Fig. 2 C. Photomicrograph of liver section of DEP (4ppm) exposed (day 21) fish. (a) necrosis (b)cytoplasmic vacuolation and (c) condensed stained nucleus (X 40 magnification).

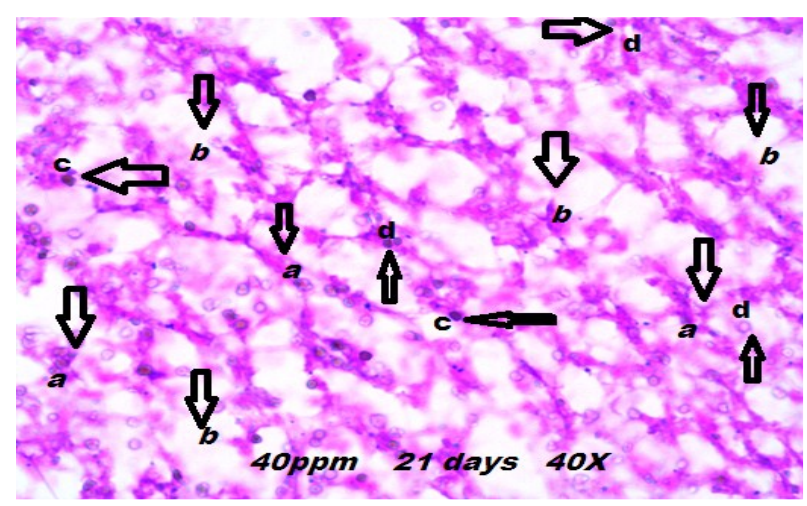

Fig. 2 D. Photomicrograph of liver section of DEP (40ppm) exposed (day 21) fish. (a) necrosis (b)cytoplasmic vacuolation (c) condensed stained nucleus and (d) shrinkage of nucleus (X 40 magnification).

varnishes and ropes in the denaturation of alcohol, perfume binders (Sonde et al., 2000). As DEP has being utilized widely for a variety of purposes, contamination of the environment via DEP cannot be excluded. Much information has talked about the effect of man-made xenoestrogenic compounds on man and wildlife (Fatoki et al., 2010). Additionally, casual usage, unintentional spillage, or expulsion of unprocessed waste matter into natural watercourse have injurious effects on the fish population and other types of aquatic life and may contribute to long term effects in the environ-

Table 2. Biochemical parameters (Mean \pm SE) in control and DEP exposed fish.

\begin{tabular}{llllll}
\hline Parameter & Days & Control & 0.4ppm & 4ppm & 40ppm \\
\hline Muscle protein (mg/g) & DAY 7 & $189.4 \pm 0.3$ & $186.7 \pm 0.7$ & $* 180.7 \pm 0.5$ & $* 176.1 \pm 0.5$ \\
& DAY 14 & $189.4 \pm 0.3$ & $* 182.5 \pm 0.8$ & $* 176.7 \pm 0.6$ & $* 173.4 \pm 0.5$ \\
& DAY 21 & $189.4 \pm 0.3$ & $* 175 \pm 0.8$ & $* 167.5 \pm 0.8$ & $* 165.7 \pm 0.8$ \\
Liver protein (mg/g) & DAY 7 & $120.4 \pm 0.2$ & $* 104.7 \pm 0.4$ & $* 92.7 \pm 0.6$ & $* 86.4 \pm 0.2$ \\
& DAY 14 & $120.4 \pm 0.2$ & $* 98.6 \pm 0.4$ & $* 87.7 \pm 0.4$ & $* 80.8 \pm 0.4$ \\
Muscle cholesterol (mg/100g) & DAY 21 & $120.4 \pm 0.2$ & $* 87.4 \pm 0.6$ & $* 75.6 \pm 0.4$ & $* 68.6 \pm 0.2$ \\
& DAY 7 & $254.4 \pm 0.5$ & $* 248.4 \pm 0.1$ & $* 241.6 \pm 0.1$ & $* 238.3 \pm 0.5$ \\
Liver cholesterol (mg/100g) & DAY 14 & $254.4 \pm 0.5$ & $* 245.3 \pm 0.5$ & $* 240.5 \pm 0.1$ & $* 231.1 \pm 0.2$ \\
& DAY 21 & $254.4 \pm 0.5$ & $* 242.5 \pm 0.7$ & $* 237.5 \pm 0.3$ & $* 227.3 \pm 0.3$ \\
& DAY 7 & $157.1 \pm 0.6$ & $155.2 \pm 0.2$ & $* 147.4 \pm 0.4$ & $* 138.4 \pm 0.1$ \\
& DAY 14 & $157.1 \pm 0.6$ & $* 149.4 \pm 0.2$ & $* 138.3 \pm 0.5$ & $* 132.7 \pm 0.1$ \\
& DAY 21 & $157.1 \pm 0.6$ & $* 146.2 \pm 0.2$ & $* 131.6 \pm 0.1$ & $* 127 \pm 0.6$ \\
\hline
\end{tabular}

*significant $(\mathrm{p}<0.05)$ 


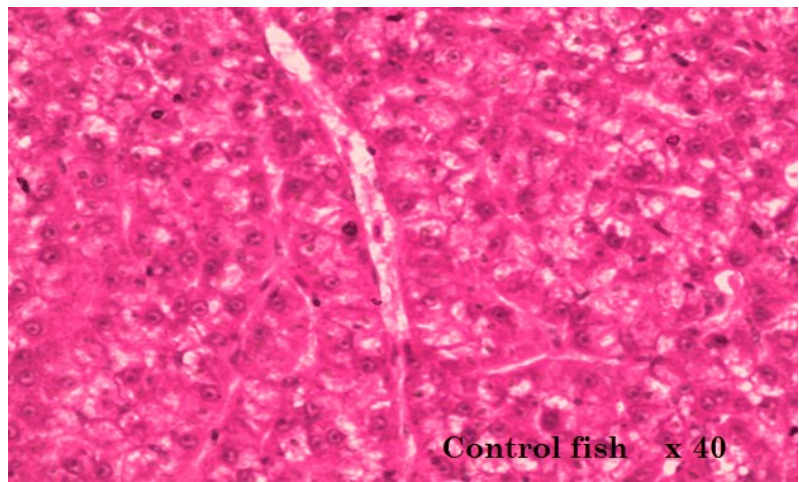

Fig. 3 A. Photomicrograph of kidney section from control fish (X 40 magnification).

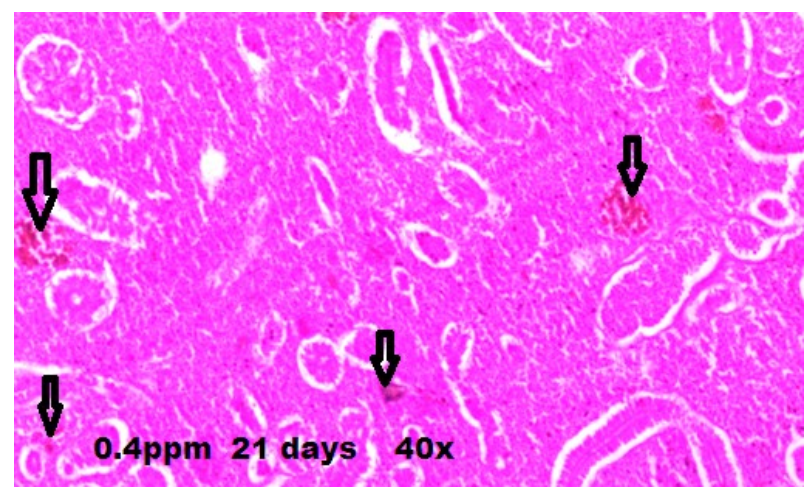

Fig. 3 B. Photomicrograph of kidney section of DEP (0.4ppm) exposed (day 21) fish showing necrosis (X 40 magnification).

ment.

Fish blood is being studied increasingly more in toxicological research and environmental monitoring as a possible marker of physiological and pathological alterations in fishery management and in examining diseases (Mulcahy, 1975). Changes in physiological and biochemical parameters of toxicant treated fish have come out as an indispensable means for water quality evaluation in the area of environmental toxicology. This is because blood in the gill has straight connection with the water medium and any adverse change in the water could be manifested in the circulatory system. These studies could be used to point out the health condition of fish and water quality.

In our study, exposure to different sub lethal concentrations of DEP $(0.4 \mathrm{ppm}, 4 \mathrm{ppm}$ and $40 \mathrm{ppm})$ caused significant $(\mathrm{P}<0.05)$ reduction in $\mathrm{RBC}$ count $(* 2.97, * 2.86, * 2.67$ and *2.51), WBC count $(* 12725.5, * 12719, * 12353.5, * 11612.5, * 11491.8$ and $* 11215.8)$, lymphocyte count $(* 22.1, * 20.8, * 20$, $* 18.2, * 16.6, * 16.4$ and $* 16)$, packed cell volume $(* 8.8$ and*8.16), mean cell volume $(* 115, * 114, * 102, * 98$ and *95), $\mathrm{Hb}$ content $(* 10.8, * 10.7$ and $* 10.4)$ and mean cell hemoglobin $(* 27.5, * 26.8, * 26.2, * 25.8$, $* 24.8$ and *24.2) of Channa striatus (Table1). According to Ikele et al, (2011), haemorrhaging of the gill when the test fish were exposed to $100 \mu \mathrm{g} / \mathrm{L}$ and 150 $\mu \mathrm{g} / \mathrm{L}$ of DEP is indicative of toxicity of this chemical.

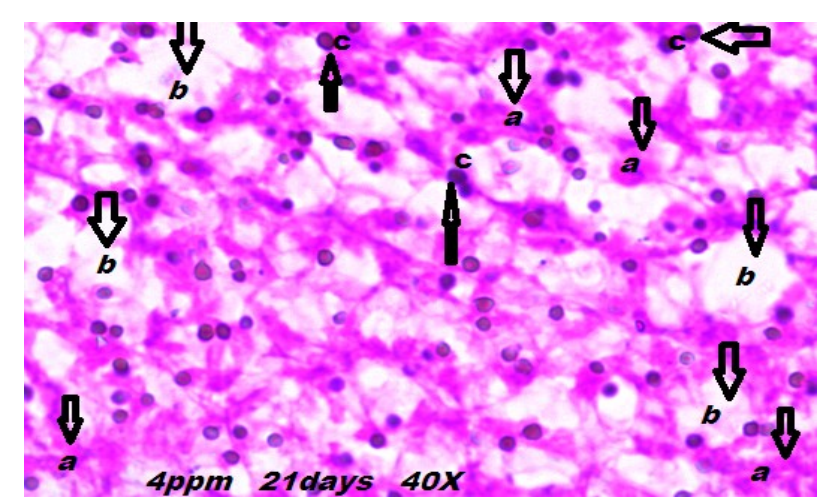

Fig. 3 C. Photomicrograph of kidney section of DEP (4ppm) exposed (day 21) fish. (a) Decreasing the size of Bowman's capsule (b) necrosis and (c) cytoplasmic vacuolation (X 40 magnification).

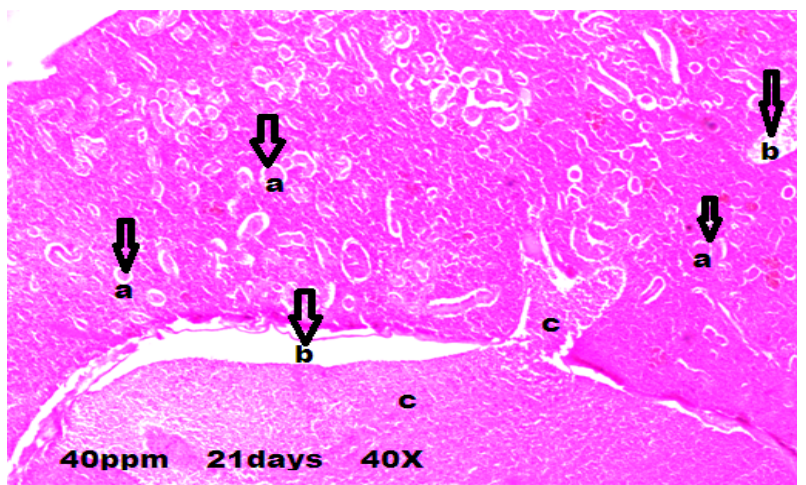

Fig. 3 D. Photomicrograph of kidney section of DEP (40ppm) exposed (day 21) fish. (a) Decreasing the size of Bowman's capsule (b) cytoplasmic vacuolation and (c) necrosis (X 40 magnification).

This is probably due to rupture of blood vessels of the gills and possible reduction in the haemotological parameters of erythrocyte count, haematocrit and mean corpuscular volume of the fish. These findings supported the present study.

The reduction observed in red blood cell count of DEP exposed fish species most likely manifests the physiological execution of haemopoietic system, which is regarded as the most susceptible marker with respect to environmental contaminants. The variation in the erythrocyte count produced erythropenia which could be ascribed to an amplified instability leading to shortening the existence of the erythrocytes.

The decreased haemoglobin concentration observed in this study is a sign of weakened oxygen release to the tissues. Obiezue et al (2014) reported that the observed decrease in the $\mathrm{PCV}, \mathrm{Hb}$ and erythrocyte count of $C$. gariepinus juvenile after 30 day exposure to DEP could be indicative of heamodilution due to erythrocyte sequesteration.

A decline in WBC was observed in DEP exposed fish species. The decrease in WBC count in our study can be attributed to reasons reported in the case of other plasticizers. Plasticizers like BPA have been shown to inhibit lymphocyte mitogenesis, MCP -1 production 
and macrophage adhesion. Although the biologic effects of these compounds are not obviously understood, BPA could have immune toxicity to Carassius auratus may be different between low and high dosages (Da-qiang YIN et al., 2007). Lymphopenia and granulocytosis have been reported after exposure to many pollutants (Svobodova et al., 1996). These changes in differential WBC count also give evidence for decreased level of nonspecific immunity in fish after acute exposure to toxic substances.

Though the mechanisms involved are not completely explained, elevated blood DEP levels are associated with impaired haem synthesis. One of the most likely contributors of this decrement and the currently most accepted major contributor to this reduction in haematological indices is impaired synthesis of erythropoietin. This glycoprotein hormone regulates both the equilibrium and synthesis of $90 \%$ of erythrocytes. DEP is an endocrine disruptive chemical. This is principally through its inhibition of erythropoietin synthesis as a result of its pathological effect. This leads to a decrease in the haematological indices (Sasaki et al., 2000).

Exposure to DEP was found to induce changes in the metabolic activity of Channa striatus. During the exposure periods, there was a marked decrease of protein content in the muscle $(* 182.5, * 180.7, * 176.7$, $* 176.1, * 173.4,{ }^{*} 167.5$ and $\left.* 165.7\right)$ and liver $(* 104.7$, *98.6, *92.7, *87.7, *87.4, *86.4, *80.8, *75.6 and*68.6) of DEP exposed fishes (Table 2). Proteins in an animal are being continually broken down and resynthesized from the free amino acid pool in the tissue. A dynamic stable state constantly exists among these two reverse procedures of protein catabolism and anabolism. Although little is known about the protein degradative systems in fish, these have been broadly categorized as lysosomal and non- lysosomal proteolytic system. Reduced level of protein in the tissue may be due to excessive proteolysis and that would in turn contribute to the elevation of free amino acids.

Levels of cholesterol in muscle $(* 248.4$, *245.3, $* 242.5, * 241.6, * 240.5, * 237.5, * 238.3, * 231.1$ and $* 227.3)$ and liver $(* 149.4, * 147.4, * 146.2, * 138.4$, $* 138.3, * 132.7, * 131.6$ and $* 127)$ of DEP exposed fish were found to be significantly $(\mathrm{P}<0.05)$ reduced (Table 2) following treatment demonstrating either an inhibition of cholesterol biosynthesis in liver or the reduced absorption of dietary cholesterol.

The liver of teleost fish is highly susceptible in showing changes in histology, metabolism and physiology following exposure to different types of environmental pollutants. Fig.2A represents the control liver with its normal architecture. There were no pathological abnormalities, where hepatocytes showed homogeneous cytoplasm and large central or sub central nucleus. Fish exposed to DEP (0.4, 4 and 40ppm) after 21 days revealed hepato cellular necrosis, cytoplasmic vacuolation, condensed stained nucleus, decreased number of nucleus in hepatic tissue and shrinkage of nucleus (Fig.2B, 2C, and 2D). Consistent with these findings, the liver of $C$. gariepinus exposed to DEP concentration showed congestion (cirrhosis), reduction of filament and enlargement of sinusoid and necrosis (Ikele et al., 2011). Liver is especially useful organ in assessing the possible impact of pollutant in fish. This is because chemical tends to concentrate there. This is also a major site for biotransformation of toxic chemicals which usually makes them less toxic and more easily excreted. Necrosis of the liver tissues in the study was observed, probably resulted from the excessive work required by the fish to get rid of the toxicant from its body during the process of detoxification by the liver. The inability of fish to regenerate new liver cells may also have led to necrosis.

Chitra and Maiby, (2014) reported that treatment of plasticizer - bisphenol A decreased the number of nucleus in hepatic tissues. Additionally, hepatic parenchyma of fish exposed to bisphenol A after 20 days showed an increase in cytoplasmic vacuolization. The widespread vacuolization might be likely due to accumulation of lipids and glycogen in hepatocytes as a result of aquatic pollution. Fig.3A represents the control kidney with its normal architecture. Fish exposed to DEP $(0.4,4$ and $40 \mathrm{ppm})$ after 21 days revealed reduced size of Bowman's capsule, cytoplasmic vacuolation and necrosis (Fig.3B, 3C \& 3D). Ikele et al (2011) reported similar findings in the kidney of $C$. gariepinus fingerlings exposed to DEP graded concentration showed tubular destruction or fusion of the tubules, pyknosis, condensation of glomeruli content and accumulation of hyaline droplets in the tubular epithelial cells. Studies reported that the concentration $50 \mu \mathrm{g} / 1$ of plasticizer- BPA has the ability to induce harmful effect on the kidney tissue of mosquito fish, Gambusia affinis and guppy fish, Poecilia reticulata and these effects are time dependent. Histological examination of the kidney, treated with Bisphenol A in both fish species showed a variety of histopathological effects; like inter tubular edema, shrinkage of glomeruli, glomerular distortion, vacuolization of tubular cells, necrosis and atrophy of renal tubules, severe congestion and blood hemolysis, fluid stagnation in renal tubules and moderate aggregation of macrophages. (Elshaer et al., 2013).In the present study, DEP as an endocrine disruptor, interferes with the synthesis of glycoprotein erythropoietin, metabolic machinery and histoarchitecture of organs of Channa striatus.

\section{REFERENCES}

Chitra, K.C. and Maiby (2014). Oxidative Stress of Bisphenol- A and its Adverse Effect on the Liver of Fresh Water Fish, Oreochromis mossambicus. International journal for scientific research., 3(4):221-224 
Cyril, A. and Eric, N. (1979). Samson Wright's Applied Physiology (12 ${ }^{\text {th }}$ Edn). Oxford Medical Publication., 2735

Da-qiang, Y., Shuang-qing, H., Ying, G., Li, W., Shu-shen, L. and Ai-qian, Z. (2007). Immunotoxicity of bisphenol A to Carassius auratus lymphocytes and macrophages following in vitro exposure. Journal of environmental sciences, 19(2):232-237

Elshaer, F.M., Abu-Shaeir, W.A. and Bakry, S.A. (2013). Histopathological changes in the Kidney of mosquito fish, Gambusia affinis and guppy fish, Poecilia reticulata exposed to BisphenolA. Egypt. J. Aquat. Biol. \& Fish, 17(4)

Fatoki, O.S., Bornman, M., Ravandhalala, L., Chimuka, L. Genthe, B. and Adeniyi, A. (2010). Phthalate plasticizers in freshwater systems of Venda, South Africa and potential health effects. Water South Africa, 36(1):117125

Finney, D. J., Ed. (1952). Probit Analysis. Cambridge, England, Cambridge University Press

Huang, P. C., Tien, C. J., Sun, Y. M., Hsieh, C. Y. and Lee, C. C. (2008). Occurrence of phthalates in sediment and biota: Relationship to aquatic factors and the biotasediment accumulation factor. Chemosphere, 73: 539544

Lowry, O.H., Rosebrough, N.J., Farr, A.L. and Randall, R.J. (1951). Protein measurement with the Folin phenol reagent. J. Biol. Chem., 193 (1): 265-275

Ikele, C., B., Mgbenka, B.O., Oluah and Ndubu, S. (2011). Histopathological effects of diethyl phthalate on Clarias gariepinus juveniles. Animal Research International., 8 (3):1431-1438

Mulcachy, M. F. (1975). Fish blood changes associated with disease: a haematological study of pike lymphoma and salmon ulcerative dermal necrosis. In: Ribelin, W. E., Migaki Madison, C. (Eds.). The pathology of fishes,
University of Wisconsin, USA, 925- 944.

Obiezue, R.N., Ikele, C.B., Mgbenka, B.O., Okoye, I.C., Attamah, G. N., Uchendu, C., Ezeamachi, E. and Onyia, C.Q. (2014). Toxicity study of diethyl phthalate on Clarias gariepinus fingerlings. Afr. J. Biotechnol., 13 (7):884-896

Sasaki, R., Masuda, S. and Nagao, M. (2000). Erythropoietin: multiple physiological functions and regulation of biosynthesis. Biosc iBiotechnol Biochem., 64:17751793

Sonde, V.D., Scouva, A., Tarapome, R., Khare. M.P., Strikar, P. and Rao, C.V. (2000). Simultaneous administration of diethyl phthalate and ethyl alcohol and its toxicity in male Spranque-Dewely rats. Toxicology, 147:23-31

Svobodova, Z., Machova, J., Kola, O. J., Vykusova, B. and Piaaka, V. (1996). The effect of selected negative factors on haematological parameters of common carp, Cyprinus carpio. L. and Tench, Tincatinca L. Proc. Sci. Papers to the 75th Anniversary of Foundation of the RIFCH VodAany, 95 -105

Umamaheswari, S. and Senthilnathan, S. (2013). Effect of diethyl phthalate on the haematological parameters of the freshwater fish Oreochromis mossambicus (Tilapia). European Journal of Zoological Research., 2:55-59

Umamaheswari, S. and Senthilnathan, S. (2014). Modulation of enzyme activity in Oreochromis mossambicus (Tilapia) exposed to Butyl benzyl Phthalate. International Journal of Fisheries and Aquatic Studies, 1(3):94 $-98$

Uren-Webster, T.M., Lewis, C., Filby, A.L, Paull, G.C. and Santos, E.M. (2010). Mechanisms of toxicity of di(2ethylhexyl) phthalate on the reproductive health of male zebra fish. Aquat. Toxicol., 99:360- 369

Zak, B. (1977). Cholesterol methodologies: A review. Clin. Chem., 23:1201-1214 